\title{
THE PUGGING OF GRASSLANDS
}

\section{G. Bowler}

Department of Soil Science, Massey University

PugGING occurs on grassland when the hooves of grazing animals penetrate the soil surface in wet conditions and cause damage to the sward. The productivity of pastures can be affected as follows:

(1) Herbage is wasted because it is pressed into the mud or otherwise rendered unpalatable.

(2) Surface campaction reduces infiltration and results in surface ponding.

(3) Pasture recovery from wet weather use is delayed and many productive plants will be replaced with weeds and poorer species.

(4) In extreme conditions animal health will be affected and young lambs may drown in the mud.

\section{THE CAUSES OF PUGGING}

Damage occurs where the saturated soil surface has a low bearing strength and is subject to intensive stocking.

Hoof pressures exerted by grazing animals vary from about 0.8 $\mathrm{kg} / \mathrm{cm}^{2}$ for mature sheep to $2.5 \mathrm{~kg} / \mathrm{cm}^{2}$ for heavy cattle at rest, but these pressures will double with movement.

High stocking rates on wet soils increase damage to pasture plants. Edmond (1962) recorded a fourfold yield reduction as a result of a threefold increase in the stocking rate of sheep from 15 to 45 sheep/ha.

Soils which have a large clay component are especially susceptible to pugging when wet and if the sward is thin. If the soil surface is loaded in this condition, deformation may occur by compression or by pugging.

When a hoof penetrates the surface it will continue until the combined compressive and shear strength of the soil is sufficient to withstand the hoof pressure or until a solid layer is reached. 


\section{THE CONSEQUENCES OF PUGGING}

The direct damage to the sward is very often underestimated. The pasture and the soil are both damaged by pugging and the effect on productivity can be significant.

Baker (1970) reported that a maximum loss of $20 \%$ of available herbage can occur under pugged conditions.

While wet weather in spring may necessitate the removal of stock from saturated pastures, efficiently under-drained fields comprised of fine-textured soils usually permit controlled grazing under most conditions.

Badly pugged surfaces are difficult to walk over, provide a rough surface for wheeled vehicles, and increase wear and maintenance on expensive machinery.

\section{HOW TO MINIMIZE PUGGING}

Pugging is most likely to occur with herds of dairy or beef cattle. If parts of a property include free-draining soils, such sites should be reserved for grazing at the wettest time of the year. Where there is no choice, one option is to spread the herd thinly over as many fields as this practice would permit.

The most positive method is to install efficient subsurface drainage systems, at least in the areas most convenient to use in winter and spring, but desirably over the whole of the wet area, to provide the maximum flexibility.

In assiociation with drainage improvements the construction of a dry-standing structure, usually termed a "sawdust" pad, can be recommended. The construction details and suggested management involved are given by Bowler (1980) .

\section{REFERENCES}

Baker, R. D., 1970. Field Drainage Exp. U nit Tech. Rep. 78/1. Grassld Res. Inst., Hurley.

Bowler, D. G., 1980. The Drainage of Wet Soils. Hodder \& Stoughton. Chap. 13.

Edmond, D. B., 1962. N.Z. Jl agric. Res., 5: 389-95. 